http://jmscr.igmpublication.org/home/ ISSN (e)-2347-176x ISSN (p) 2455-0450

crossref DOI: https://dx.doi.org/10.18535/jmscr/v8i1.153

\title{
Spectrum of Histopathological patterns of breast lesions studied over a period of 4 years - an observational study in a tertiary care hospital
}

\author{
Authors \\ Suhail Farooq, Salma Gull, Zarkah Nabi, Sheikh Bilal \\ GMC Srinagar, India
}

\section{Introduction}

The diseases of the breast are much common and include problems related to pregnancy and lactation $^{1}$, inflammatory conditions, nonneoplastic proliferative lesions and various neoplasms. The purpose of the current study is to review all cases of breast diseases seen in our department over a period of four years and to determine the pattern of histo-pathological diagnosis of breast diseases in our setting.

\section{Methods}

This is a retrospective study conducted in the postgraduate department of pathology, Government Medical College, Srinagar, over a period of 4 years from $1^{\text {st }}$ January, 2015 to $31^{\text {st }}$ December, 2018. A total of 498 cases were included in the study. All the required hospital based records and the corresponding H\&E stained slides were retrieved and reviewed. Data regarding the age, laterality of the lesion and prominent histopathological morphology were analyzed.

\section{Results}

Out of 498 cases of lesions of the breast, 390 (78.3\%) cases were benign while 108(21.6\%) cases were malignant. The benign to malignant ratio was 3.16:1. The mean age of benign breast disease was 25 years with age range of 14 to 48 years. The mean age of malignant breast diseases was 52 years with age range of 28 to 78 years. There were 479 cases of the female breast and 19 cases of male breast.

Among the benign breast diseases, inflammatory lesions comprised $48(12 \%)$ cases and benign breast lesions comprised $342(88 \%)$ cases, with the mean age of these two being 30.33 years and 27.8 years respectively.

Fibroadenoma was the commonest lesion affecting the breast and was diagnosed in $237(60.56 \%$ of benign lesions and $47.59 \%$ of all lesions) cases. The age range was between 14 and 50 years with a mean of 24.46 years. There was a left sided preponderance with 158 cases occurring in left breast.

Fibrocystic disease was the second most common benign lesion among female patients comprising 16 (4\% of benign cases and $3 \%$ of all) cases with the age range of 26-50 years. Other benign lesions included Intraductal papilloma, Epithelial hyperplasia and Adenosis. There were 9 cases of benign phyllodes with the mean age of 35 years. Non specific or normal biopsies were found in around 8 cases. 
Among the inflammatory lesions abscess and acute mastitis were most common and constituted the second major category among the non malignant cases $(12 \%)$. There were 27 cases of acute mastitis and 11 cases of Abscess. 8 cases of granulomatous mastitis and 2 cases of plasma cell mastitis were also seen.

18 cases of breast lesions were seen in male patients out of which17 were gynecomastia. Mucinous carcinoma of the breast was diagnosed in one of the patients.

Breast cancer was seen in around 108 cases, among which invasive ductal carcinoma represented 102 cases, invasive lobular carcinoma and mucinous carcinoma represented 1 case each. There were 5 cases of in situ ductal carcinoma. Breast cancer comprised around $21 \%$ of the cases.

\section{Discussion}

There is a wide spectrum of diseases both benign and malignant affecting the breast from teen age to throughout the adult life. The incidence of these presentations varies in different geographical areas according to the spectrum of breast diseases encountered. Overall, breast problems are commonly see in females as compared to males ${ }^{2,3}$. Similarly, in this study females were more affected than males with female to male ratio 80:1.

Benign breast diseases are significantly more common than the malignant conditions worldwide. In this study Benign Breast diseases comprised $78.3 \%$ of all breast lumps with benign to malignant ratio $3.16: 1$ which is comparable to other studies $^{4,5}$. Benign breast lesions (342) were found to be more common than inflammatory lesions (48) in our patients which is consistent with other reports ${ }^{4,6,7}$.

The median age of the patients was 28.17 with the age ranging from 13 to 67 years. Most of the patients were in 21-30 years age group as reported in other studies. ${ }^{8,9}$ Another study found majorty of patients in 31-40 years age group. ${ }^{10}$ There was left sided predominance of disease. About $46.5 \%$ occurred on the left, $38.7 \%$ on the right, while $1.2 \%$ were bilateral. This agrees with many reports. ${ }^{6,11}$ Few of the reports show right sided predominance. $^{12}$

In agreement with many studies Fibroadenoma was the most common lesion and constitute $(48.82 \%)$ of all cases and $60.56 \%$ of benign lesions. ${ }^{7,8,9}$ Similar frequency of FA was found in some reports but some reports showed lower frequency. 4,6

The high frequency of FAs has been reported in Saudi $\mathrm{Arab}^{4,8}$ India $^{14}$ and black American ${ }^{15}$ and African females ${ }^{9,11}$ and contrast with the lower frequency in Western white females ${ }^{13}$.

The cause of higher frequency of FA in our females is not clear but racial predisposition could be a factor. Most of our cases were in $3^{\text {rd }}$ decade of life followed by $2^{\text {nd }}$ decade, as also found by others. ${ }^{8}$ However some reported peak in the $2^{\text {nd }}$ decade. $^{9} \quad$ It is usually a disease of early reproductive life and $98.45 \%$ of our cases were below 40 years of age.

In accordance with many authors fibrocystic change was the second most common benign lesion and constitutes $4 \%$ of benign lesions. ${ }^{4,} 8,16$ Fibrocystic change occurs predominantly between 26 and 50 years of age $(76.5 \%)$

Inflammatory lesions were less common than benign breast lesions in this review and comprised $12 \%$, This frequency is comparable to many other studies. ${ }^{5,17,}{ }^{18}$ Acute mastitis and Breast abscess were the commonest inflammatory lesion. Peak incidence was in $3^{\text {rd }}$ decade and $89.66 \%$ were less than 40 years of age, reflecting the association of this lesion with pregnancy and lactation. Chronic mastitis comprised $4.53 \%$ cases, figure consistent with other studies.

Granulomatous inflammatory changes in the breast can be related to specific infections like mycobacterium tuberculosis, foreign material such as silicon or suture material, trauma or systemic autoimmune disease. Tuberculosis is a rare disease affecting breast in $1.48 \%$ cases as observed by Malik et al in their study. ${ }^{17}$ In the present series, it accounts $1.23 \%$ of all breast 
lesions. A much higher figure of $23 \%$ was however reported in the literature. ${ }^{18}$

Gynaecomastia was the only breast disease of males in this study. It comprised $3 \%$ of all breast lesions which compares well with the $1 \%$ quoted in Caucasian series. ${ }^{19}$

Breast cancer represented $21 \%$ of breast lesions with predominance of ductal carcinoma. The most common pattern of breast cancer in the present study was ductal carcinoma representing $29.1 \%$, followed by lobular carcinoma representing $4.4 \%$ and mixed $(1.9 \%)$. This is comparable to other studies $^{20}$. In the current study, breast cancer was mostly found among elderly patients ( $>41$ years of age) $(63.2 \%)$ and less in younger patients $(<40$ years) $(18 \%)$ with the mean age of onset of 48.6 years. $^{21}$

\section{Conclusion}

The profile of breast lesions in the present series follows a pattern similar to that of other developing countries. The commonest breast lesion was fibroadenoma followed by Invasive ductal carcinoma, inflammatory lesionsand then other benign lesions.

\section{References}

1. Mahmood A, Ahmed M, Jamal S. Role of cytological grading in the management of breast lump. J Cll Pysicians Surg Pak 2003; 13(3): 150-152.

2. Lester SC. The Breast. In: Robbins and Cotran Pathologic basis of disease. $9^{\text {th }}$ edn. Philadelphia: Elsevier Saunders, 2015; 1043-1071.

3. Kumar R. A clinicopathologic study of breast lumps in Bhairahwa, Nepal. Asian Pacific J Cancer Prev 2010; 11: 855-858.

4. Jamal AA. Pattern of breast diseases in a teaching hospital in Jeddah, Saudi Arabia.Saudi Med J 2001; 22(2): 110-113.

5. Amin TT. Histopathological patterns and risk of female breast lesions at a secondary level of care in Saudi Arabia.Asian Pacific J Cancer Prev 2009; 10:1121-1126.
6. Al Nazer MA. Outline of breast diseases in Qatif Central Hospital. Kuwait Medical Journal 2004; 36(3): 182-185.

7. Hussain N, Ayaz B, Nadia N, Ali Z. Pattern of female breast diseases in Karachi. Biomedica 2005; 21: 36-38.

8. Amr SS, Sa'di AR, Ilahi F, Sheikh SS. The spectrum of breast diseases in Saudi Arab females - a 26-year pathological survey at Dhahran health center. AnnSaudi Med 1995; 15(2): 125-132.

9. Ohene-Yeboah MOK. An audit of excised breast lumps in Ghanaian women. WAJM 2005; 24(3): 252-255.

10. Parajuli S, Koirala U, Khatri R, Acyarya L, Suwal A. Histomorphological spectrum of breast lesions. J Nepal Health Res Counc 2011; 9(1): 48-51.

11. Shirley SE, Mitchell DIG, Soares DP, James M, Escoffery CT, Rhoden AM, Wolff C, Choy L, Wilks RJ. Clinicopathologic features of breast disease in Jamaica - findings of the Jamaican breast disease study, 2000-2002. West Indian Med J 2008; 57(2): 90-94.

12. Tesfamariam A, Parilla F, Paulos E, Mufunda J, Gebremichael A. Clinicohistopathological evaluation of breast masses and profile of breast diseases in Eritrea - a case of poor concordance between clinical and histological diagnosis. J Eritrean Med Assoc 2008; 3(1): 32-35.

13. Ellis H, Cox PJ. Breast problems in 1,000 consecutive referrals to surgical outpatients. Postgrad Med J 1984; 60: 653656.

14. Rangabashyam N, Gnanaprakasam D, Krishnaraj B, Manohar V, Vijayalakshmi SR. Spectrum of benign breast lesions inMadras. J R Coll Surg Edinb 1983; 28(6):369-373.

15. Raju GC, Jankey N, Narayansingh V. Breast disease in young West Indian women - an analysis of 1051 consecutive 
cases. Postgraduate Medical Journal 1985; 61: 977-978.

16. Abdulkareem KF, Ali AH, Wadi RK Breast lumps in Basrah - a retrospective Study. Al Taqani 2010; 23(3): 37-42.

17. Malik MAN, Salahuddin O, Azhar M, Dilawar O, Irshad H, Sadia, SalahuddinA. Breast diseases; spectrum in WahCantt; POF Hospital experience. Professional Med J 2010; 17(3): 366-372.

18. Chiedozi LC, El Hag IA, Kollur SM. Breast diseases in the Northern region of Saudi Arabia. Saudi Med J 2003; 24(6):623-627.

19. Funderburk WW, Rosero E, Leffall LD. Breast lesions in blacks. Surg Gynecol Obstet 1972; 135(1): 58-60.

20. Ferlay Jacques, et al Ëstimates of worldwide burden of cancer 2008: GLOBOCAN 2008', International journal of cancer Vol. 127, No.12, 2010, pp 28932917.

21. Mansoor Ibrahim. Journal- Pakistan Medical Association.Vol. 51. No.7,2001, pp 243-246. 